\title{
Rousseau y los fundamentos de la democracia en El Salvador
}

\author{
Picardo Ribera
}

\section{Nuestra problemática actual y Rousseau}

La idea de que los Acuerdos de Paz constitulan una forma de pacto social y de que en El Salvador un futuro democrático y pacifico dependería de la solidez del nuevo consenso nacional alcanzado, ha merecido -desde que fue expresada en Chapultepec el 16 de enero de 1992una general aceptación y ha sido, desde entonces, innumerables veces repetida. Para muchos, la idea parecia novedosa, y son pocos' los que han reparado en su clara conexión con la concepción de contrato social que desarrollase, a mediados del siglo XVIII, un agudo pensador: Juan Jacobo Rousseau.

Por otra parte, desde que terminó el conflicto, la democracia ha levantado tan unánimes adhesiones, que tal pareciera que fuese éste un país lleno de "demócratas de toda la vida". La real sinceridad de dichas posiciones está todavla por verse, pero se reconoce al menos que faltan tradiciones y cultura democrática, donde la democracia pueda echar ralces. Hay conciencia de que la sola reforma de las instituciones no basta; de que se precisa de nuevas práclicas, actitudes, costumbres y valores; de que a un nuevo estilo de hacer politica, deberá corresponder un esfuerzo de educación ciudadana de amplio alcance. Se trata, nuevamente, de una problemática típicamente rusoniana - planteada audazmente en 1762 en el Emilio- frente a la que está confrontado El Salvador de nuestros dias: la de cómo educar al hombre para la sociedad, la de cómo incidir desde la educación en la comunidad, desde el individuo en 
la colectividad, desde la ética en la polltica.

En tercer lugar, cabe decir que, pese al actual entusiasmo ideológico que la democracia despierta por nuestros lares, como si fuera la solución a todos los problemas, las cosas no son tan sencillas. En muchas de las naciones con tradición democrálica, sus ciudadanos hace tiempo que "vienen de regreso": sólo la mitad participa en los procesos eleccionarios y, de ellos, según las encuestas, la mitad no cree que aquéllos sirvan para mayor cosa. Mientras en El Salvador el "cansancio de la guerra" tuvo el saludable efeclo de contribuir a acelerar la solución negociada, en otros paises el cansancio de la política - ol llamado "desencanto"- sólo ha aumentado la alienación y el individualismo. Aún más paradojico: si bien en El Salvador la guerra ha traido democracia, en Bosnia, inversamente, podriamos decir que la democracia ha traldo la guerra. Por tanto, decir democracia no es suficiente; habrá que ver sobre qué bases, cuáles sus límiles y sus riesgos. ${ }^{2}$ En el fondo, sigue palpilando la inquietante pregunla rusoniana, de si es lactible la democracia en medio de grandes desigualdades económicas y sociales. ¿Puede, una sociedad como la salvadoreña, volverse más democrática si no se hace, al mismo tiempo, más igualitaria?

\section{Rousseau: el hombre y su época}

Lo primero que cabe decir de Rousseau es que, aunque ya en su liempo fue reconocido como un gran pensador, nunca perteneció propiamente al mundo Inlelectual de su época. Nacido en 1712 en Ginebra, Sulza, fue coetáneo de Voltaire, de Dlderot, de d'Alambert y del resto de enciclopedistas y grandes autores de la llustración. Sin embargo, su relación con ellos fue siempre diflcil. Habla demaslada originalidad y radicalidad en sus ideas, como para que fuera aceplado por los teóricos de la sociedad burguesa. Por otro lado, el modesto origen y condición social de Rousseau - quien, por muchos anos, tuvo que dedicarse a dar clases de música para poder sobrevivir- era, para algunos, otro mollvo de sospecha. Igualmente desdenosa era la posición de Rousseau respecto a ellos. "Nunca he aspirado a ser fibsofo - exclamaba en su correspondencia privada - nunca me hice pasar por tal; no bo he sido, ni bo soy, ni to quiero ser".

Mas, entonces, ¿como se consideraba a si mismo quien, con justa razón, ha sido apreciado por la posteridad como uno de los fitósolos más importantes de la modernidad? "Soy un hombre poco instruido que nunca se ha preocupado de serlo - decla con sincera modestia- pero que a veces tiene sentido común y siempre ama la verdad". Puede apreclarse en esa actitud, no solo su rechazo a formar parte de una 
élite, sino también la posición del intelectual que elige escribir para la genle llana, para el pueblo, y no para los sabios y eruditos.

En el siglo llamado "de las luces", el siglo de la razón y la filosoffa, esa posición personal constiluía, sin duda, otra faceta de la rebeldla rusoniana. También revela un profundo antidogmalismo -que caracteriza la obra de Rousseau- y del cual él mismo era consciente, como lo refleja su desprecio por aquellos filósofos "orgullosos, alirmativos y dogmáticos, que no ignoran nada".

En un siglo en que la filosolia ayudaba a dernumbar un mundo teudal irracional, se exallaba la razón, mas Rousseau apelaba al sentimiento. En su novela pedagógica "Emllio", (1762), escribió: "aunque los filósofos del mundo probasen que estoy equivocado, si sentis que tengo razón no necesilo más". "Existir, para nosotros es sentir -argumentabay nuestra sensibilidad es indiscutiblemente anlerior a la razón misma". En "Confesiones" -obra que no tue publicada sino hasta 1780, dos anos después de su muerte- insistla: "puedo pasar por allo hechos, confundir el orden y errar en las fechas; pero respecto a aquéllo que he sentido no puedo equivocarme"." Es por ello que Rousseau ha sido considerado como un precursor del romanticismo, el movimiento artistl$\infty$ y literario que el siglo siguiente reivindicarla, frente al mundo burgués racionalizado y puritano, los aspectos irracionales de la esencla humana.

Frente a la ideologla de la época que, imbuida de optimismo racionalista, confiaba absolutamente en el progreso de la humanidad, Rousseau reacciono rechazando con vehemencia lales supuestos. En su primera obra, "Discurso sobre las Clenclas y las Artes", (1750), con la que concursó para el Premio de la Academia, el cual obtuvosostuvo la tesis contraria: no ha habido progreso, sino degradación. Es decir, la historia de la humanidad, llena de violencias y de Irracionalidad, nos ha heredado un mundo cada vez más inhumano, que va camino de una lotal depravación. La llamada "civilización" será sinónimo de progreso sólo sl es puesta verdaderamente al servicio del hombre; de lo contrario, los pretendidos progresos culturales, lécnicos y cientifloos, se convierten en realidad en fuente de mayores desdichas. Rousseau Insistiria en esa misma idea en su "Dlscurso sobre el origen y fundamentos de la deslgualdad entre los hombres" -presentada asimismo para el Premio de la Academia, en 1754- y la mantendrla en 1762, en su obra principal, "El Contrato Soclal", desde la primera Irase con la que daba inicio a la misma: "El hombre ha nacido libre $y$, sin embargo, por todas partes se encuentra encadenado". 


\section{La crftice rusonlana al absolutiemo y al liberallemo}

La crillca nusonlana a la teorla del absolutismo, delensora del mundo feudal, fue implacable. Contra Hobbes argument6: "SI es la fuerza la que hace el derecho, ¿qué es un derecho que perece cuando la fuerza cesa? (...) Sl es preciso obedecer por la fuerza entonces no es necesario obedecer por deber. Después afirmaba rolundo: "la fuerza no constituye derecho; no se está obligado a obedecer sino a los poderes legítimos."

El análisls rusonlano deshacia tamblén la noción -común a Hobbes y a Locke- de "estado de guerra". Para Rousseau, éste, sencillamente, "no existe". Al respecto daba dos tipos de argumentos: por su duracion ("los combates son actos... no hay una relación suficientememle conslante") y, en segundo lugar, por su esencia ("la guerra no es una relaclón de hombre a hombre, sino de Estado a Estado; los particulares sólo son enemigos incidentalmente... cada Estado no puede tener de enemioos hombres, sino otros Estados, pues son cosas de diversa naluraleza').

Rousseau no sólo rechazó la idea del estado natural como un estado de guerra, sino que además llenó de un contenido distinto la noción de estado de la naluraleza, en contraste con Hobbes y también con Locke. -Un estado que ya no existe, que a lo mejor nunca existio, que probablemente no existirá jamás", dijo de él en El Contrato Social. El estado de la naturaleza carece, en la concepción rusonlana, de una lemporalidad histórica. Posee - tal como ha enfatizado Sánchez Vázquez- un carácter ideal: no es un punto de partida, es una meta. Para Rousseau la sociedad debe ser aconde con la naturaleza humana; al delinear los rasgos esenciales del hombre, plantea una mela ideal o arquetipo humano que llama hombre de la naluraleza", al cual debe ajustarse el ideal de sociedad."

Rousseau criticó lambién duramenle la lesis del despotismo ilustrado de la limitación de libertades individuales -en aras de alcanzar la seguridad-compartida parcialmente por la leorla liberal de Locke. "Se dirá que el desspola asegura a sus súbditos la tranquilidad civil. Sea. También se vive tranquilo en los calabozos... los griegos encerrados en el antro del Clclope vivian tranquilos esperando que les llegase su lumo de ser devorados". Después de esta irónlca refutación conclula Rousseau esa parte de "El Contrato Social" con una lesis esencial: "Renunciar a la libertad es renunciar a la cualidad de los hombres".

O sea, siendo la libertad lo que esencialmente diferencia al hombre de los animales, la libertad es irrenunciable; ol privarse de ella significarla un retorno a la animalidad y la renuncia a vivir en sociedad, pues 
esta, por delinklion, es humana, no puede ser sino humana, slendo un contrasentido una sociedad no humana, inhumana o deshumanizada. Rousseau, por supuesto, rechazaba la esclavilud -"el derecho de esclavitud no solo es llogltimo, es absurdol" - y el imperialista "derecho de conquista", el cual, "no tiene otro tundamento que la ley del más tuerte". -Slempre habrá una gran diferencia -recordaba el ginebrino- entre someter a una mullitud y regir una sociedad".

La radicalidad rusoniana estaba, no obstante, en llevar esa misma Kogica más alla, hasta cuestionar los fundamentos mismos del liberalismo y de la sociedad burguesa: la propiedad privada. Sánchez Vázquez, al analizar el pensamiento rusoniano - "estáis perdidos si olvidáis que los frutos son para lodos y que la tierra no es de nadie"- considera como parte del mérito de Rousseau el thaber vinculado los males de su sociedad con la aparición de la propiedad privada"?

Cabe advertir que la critica rusoniana se centraba en la propiedad de la tierra, y que difícilmente podia ser de olro modo en la segunda milad del siglo XVIII, cuando ni el capitalismo, ni el proletariado, hablan alcanzado el nivel de desarrollo propio de la revolución industrial. De ahf que, aunque hizo un enfoque del problema, éste resulta superficial, lo que se advierte en las diversas relerencias de Rousseau sobre este tema: "Entre estos tipos de desigualdades (...) la riqueza es la última a las que éllas se reducen al tin"; "existen pobres sólo porque exislen ricos"; "mientras los pobres mueren por sus necesidades, los ricos mueren por sus excesos"; "es mejor, creedme, vivir en la abundancia que en la opulencia"; "la lgualdad rigurosa no es posible; debe haber moderación en los ricos y conlormidad en los pobres". Estos pensamientos inspirarian después a muchos relormadores sociales y socialistas ulópicos.

\section{El método rusonlano: la subversión de categorlas teórlcas}

Aunque los escritos rusonianos permilen, por lo general, varias interpretaciones -incluidas una lectura relormista y una revolucionariapuede afirmarse, no obstanle, que en su propio mélodo está conlenido un ingrediente inequlvocamente subversivo. Rousseau usa palabras y conceplos comunes a su época; mas, sin embargo, en el contexto rusoniano los términos aparecen trastocados, adquieren otro contenido o cambian de sentido, incluso para senalar lo contrario de lo que usualmente expresan.'

Ya advertimos algo de eso cuando nos referimos a la utilización rusoniana de la expresión "estado de la naturaleza". Veamos otro ejemplo sencillo: la forma cómo manipula el término "soberano", comúnmente empleado como sinónimo de monarca. Rousseau niega lal concepción 
haciéndolo por la vla de una afirmación de signo opuesto; soberano pasa entonces a contener un significado contrarb, convirtiéndose, en la alquimia tedrica rusoniana, en sinónimo de pueblo. Es como si no le bastara a Rousseau con la proclamación de la soberania popular y of consiguiente rechazo de una soberania individual dinastica, impuesta sobre los pueblos: habla que arrebatarles también, a reyes y emperadores, la apropiación que hablan hecho de las palabras "soberanla" y "soberano".

Por otra parte, si se compara la concepción rusoniana del poder con el planteamiento de Hobbes, puede apreciarse la similitud entre ambos. En los dos casos se trala de un poder irrestricto, ilimitado, absoluto. Para Hobbes, delrás de esla concepción estaba el inlento reaccionario de legitimar una monarqula absolutista que pretendla delentar un poder total. Pues bien, no le baslaba a Rousseau con rechazar lal prelensión: la subvierte conservando sus mismas premisas para, utilizando las armas teoricas de su contrario, sustentar la tesis más extremadamenle opuesta, la de un poder popular que sea -asl como era en Hobbesindivisible, inalienable, intransferible e indelegable; un poder que será "siempre recto", que "no puede errar".

Un tratamiemo similar reclbió Locke, el padre del liberalismo, en manos de Rousseau. Mientras aquél rechazaba el "origen divino" del poder monárquico, éste refutará el "origen racional" del poder burgués y la idea de que una monarqula parlamentaria se constituya en la alternaliva a la monarqula absolulisla. "Antes de ver el acto por el cual un pueblo elige un rey" - argumenla el aulor que nos ocupa- "conviene examinar el acto por el cual un pueblo es tal pueblo". La genialidad de Rousseau estriba en que usó contra Locke el mismo artilicio teórico que aquél empleó: o sea, la idea de un conlralo social, como origen y fundamento de la sociedad.

Ahora bien, el contrato que describe Rousseau es harto especial. Consiste en "la enajenación tolal, con todos sus derechos, a loda la humanidad"; cada individuo coloca "todo su poder y su persona bajo la suprema dirección de la volunlad general"; este especial contrato tiene entonces la virtud de que "dándose cada cual a todos, no se da a nadiel". En realidad -como alinadamente ha hecho notar Althusser- se trata de un no-contrato. No hay propiamente parles contratantes en el sentido en que aparecen en un contralo juridico; en el momento de electuarse, se tiene la Parte I (los individuos) pero la Parte II (la comunidad) no existe todavía, sino que es resultado del conirato. ${ }^{10}$ Estamos pues anle una convención teórica, por medio de la cual se reafirman las lesis de soberania popular postuladas por Rousseau y, lo que es más 
importanto, resultan refutadas las tesis liberales de soberania limilada. Su sistema teorico, por tanto, lejos de ser una variedad de contractualismo (tal como en forma superficial ha sido caracterizada a menudo la obra rusoniana) deberla más bien ser considerada como una refutación de las teorlas contractualistas clásicas.

\section{La problemátlca especiflca de Rousseau}

En la obra rusoniana puede rastrearse, a través de los sucesivos temas de be que se ocupa el autor, un hillo conductor que la atraviesa desde el primer hasta su último libro y que le da coherencia al conjunto: su problemática.

Recordemos como en su primer Discurso planteaba el proceso de degradación de la humanldad, una vez ésta ha perdido el sentimiento de fraternidad, de ahl el reto de recuperar la capacidad de solidaridad frente a otro ser humano, de la solidaridad como especie. En su segundo Discurso es el lema de la igualdad el que concentró la alención de Rousseau: no puede ser legilima una sociedad esencialmente desigual, un sistema fundado sobre grandes desigualdades sociales. En su obra capital, "El Contrato Social", el problema central es el de la libertad, y sus vinculos esenciales con la soberanla popular y la igualdad social. Visto asI, no debe sorprender que los dirigentes de la revolución francesa se inspirasen en el pensamiento rusoniano a la hora de concebir como lema la famosa trilogla: libertad, igualdad, Iraternidad."

En el "Emillo" está planteada una via de resoluclón práctica a esta problemática: cambiar al hombre -oducándolo- para cambiar a la sociedad. En Rousseau, para algunos, esto es coherenle: "En el Emilio, igual que en el Contrato Social, se trata también de que el hombre vuelva a la naturaleza, entendida como ideal de lo humano; pero en el Emilio no se trata del Estado sino del individuo. (...) Puesto que el principal derecho nalural del hombre es la libertad, la educación debe ser libre". ${ }^{12}$ Eso mismo es, en cambio, vislo por olros como una ingenuidad o criticado como "una evasión hacia adelante en la ideologla"." Otros analistas, por el contrario, ponderan como un aporte signilicativo su planteamiento de este problema: en Rousseau, como en Marx, "la liberación de la sociedad avanza al mismo rilmo que la liberación de los individuos"; ${ }^{14}$ "Rousseau tiene el mérilo de haber sefialado que la individualidad y la socialidad no son dinamismos opuestos sino que, bien entendidos, resultan más bien complementarios... Cuanto más se socialice el hombre, más logra su propia realización personal" ${ }^{15}$ Otro autor interpreta el Emilio en el sentido de que el objelivo de la educación debe ser "preparar al ser humano para vivir en sociedad, sin que ésta logre corromper en él al 
'hombre natural'... educar para una sociedad no significa adaptar al hombre para esa sociedad". ${ }^{16}$

Regresemos, sin embargo, a su obra principal, objeto de las más variadas interpretaciones. Para unos en el Contrato Soclal la pregunta central eslá en "¿qué es y cómo conseguir una sociedad legítima?"m7; o, expresado de otra forma: "Rousseau sentó las bases para un nuevo principio de legitimación";"10 dicho con mayor precisión: "la tesls central de Rousseau es que una sociedad desigual es una sociedad irracional", for tanto, el problema fundamental que nos plantea Rousseau es el de la creaclón de una sociedad igualitaria, la cual "no es un punto de partida, sino una meta a alcanzar"." En un estudio que es ya un clásico, el italiano della Volpe caliticaba a Rousseau de "descubridor de la libertad igualitaria", base a su vez de la concepción de soberanía popular, la cual "es de por sl una doctrina tradicionalmenle burguesa, cuya formulación racional y coherente pertenece a Rousseau y no a Locke"; sin embargo, cuando dicho analisla se formulaba la pregunta ¿en qué la problemática rusoniana trasciende la revolución burguesa?, reconocia: "el problema de la libertad igualitaria sigue siendo un problema rear.:0 Para Colangelo Ta problemálica de Rousseau es el análisis crítico de la desigualdad social"; la igualdad es su "nudo teórico fundamental", desde el cual "configura una sociedad alternativa a la presente".21

\section{La utopla rusonlana: fundamentos de una socledad alternatlva}

Según la teoria liberal se da una antinomia entre igualdad y libertad, ante la cual el liberalismo responde privilegiando a esla última y sacrificando la primera; para las doctrinas igualitaristas -desde Babeuf hasta las corrientes de manxismo "ortodoxo" o pro-soviético- la relación serla a la inversa. Rousseau niega tal dicotomia, eludiendo asl el dilema: la una supone a la otra, la libertad es esencial al hombre y su primer derecho, pero la igualdad es condición de la libertad, "la liberlad no puede subsislir sin ella".

El mórilo de Rousseau está en haber descubierto el problema y haberlo planleado correctamente. Ahora bien, conocerlo no es lo mismo que haberlo solucionado. El problema de la relación entre igualdad y liberlad sigue ahl, casi dos siglos y medio después de que fuera formulado por Rousseau, sin haber sido solucionado; incluso, seguimos ignorando mucho sobre sus vlas de solución. Ni el capilalismo liberal ha desembocado en una sociedad verdaderamente libre, ni tampoco las sociedades de "socialismo real" consiguieron ser propiamente igualitarias; mucho menos han podido ser combinados ambos ingredientes -libertad e lgualdad-, a fin de realizar alguna forma de libertad 
igualitaria, como la concebida utópicamente por Rousseau.

Durante la revolución francesa diversas corrientes manifestaron Inspirarse en Rousseau. Ahora bien, ¿qué tan lieles a su pensamiento tueron?, ¿qué lanto se acercaron con sus proyectos políticos al ideal de socledad Imaginado por Rousseau? El Manifiesto de los Iguales" de Babeut planté un radical lgualitarismo nivelador: dado que "la lgualdad de derechos es sólo una igualdad sobre el papel", reclamó la "lgualdad de estómagos" y exigió el "consumo igual", transformó el bien común" rusoniano en "comunidad de blenes", la "voluntad general" en voluntad popular. Maxx reaccionaría contra esas tendencias que ven el sociallsmo girando en torno a la distribución", 2 que solamente en apariencia son radicales y que no pueden sino quedar reducidas a una opción reformista: "no se trata de corregir el mecanismo de la repartición, sino de reemplazar el actual sistema de la producción".

Sin embargo, no queda claro sl la crilica de Marx, enfilada contra las corriemtes igualitaristas y las teorías del socialismo utópico, alcanza también a Rousseau. Para el marxista della Volpe, el "igualitarismo no nivelador" nusoniano sería prácticamente una anticipación del "socialismo cientffico": Marx planteó como ideal de sociedad comunista "de cada quien según sus capacidades, a cada cual según sus necesidades"; Rousseau habla escrito algo bastanle similar: "siendo las necesidades naturales las mismas en todas partes, los medios para proveerlas deben ser iguales en todas partes". Para el socialismo -etapa intermedia o de transición entre capitalismo y comunismo, en la que subsiste aún el Estado- Marx prevela otro principio: "a cada quien según su trabajo"; pues bien, como ha destacado Colangelo, algunas ideas rusonianas parecen encajar con esa concepción: "desearía que el Estado tuviera todo y que cada uno sólo tuviera su parte de los bienes comunes en medida proporcional a sus servicios" —escribió Rousseau-, "el rango del ciudadano debe estar regulado, no por su mérito personal... sino por los servicios reales que de él recibe el Estado y que son susceptibles de una medición más exacta".

Ahora bien, ¿como concibe Rousseau ese Estado del que habla? En primer lugar, su concepción coincide con lo que hoy denominamos Eslado de Derecho: "Llamo república a todo Estado regido por leyes; todo gobierno legltimo es republicano". En segundo término, el poder legislativo corresponde por su naturaleza al soberano, debe estar en las manos del pueblo; es to que se desprende del ataque rusoniano contra aquéllos que "confunden la ley con la aplicación de la ley, confunden la soberanía cuando es sólo su ejecución".

Relacionado con lo anlerior, debernos precisar que, para el autor que 
nos ocupa, república no equivale a democracia. Es más, Rousseau se inclinaba por la aristocracia -entendida en sentido clásico como gobierno de una minorla - a la que consideraba como "el orden mejor y más natural", (aunque prefiria la electiva, a la nalural y a la hereditaria). Mientras en la aristocracia gobierno y soberano están diferenciados, en la democracia rusoniana el poder ejecutivo iría unido al legislativo.

Rousseau hizo uno de los más bellos elogios que se hayan hecho nunca de la democracia, pero no la recomendo: "Si hubiese un pueblo de dioses se gobernarla democrálicamente; mas, un gobiemo tan perlecto no es propio para los hombres". Esta sugerente irase nos motiva una pregunta: ¿serla la democracia radical en la que piensa Rousseau una forma de gobiemo del fuluro, cuando los hombres, que en periodos revolucionarios pretenden "asaltar el cielo", 24 hayan además aprendido a comportarse como dioses?

Por último, debe decirse que la forma de gobierno es, para Rousseau, algo secundario; a él lo que le interesa es el contenido más que la forma. Lo que verdaderamente le importa es que la sociedad se rija por la voluntad general, ésa que "siempre tiende a la utilidad pública", la que coincide con el "interés general" o "bien común". Debe tomarse en cuenta que "lo que generaliza la voluntad es menos la cantidad de volos que el interés común que los une". Incluso es posible que el pueblo se equivoque, o que sea engafiado, y que la voluntad de todos (o de la mayoria) no coincida con la volunlad general". La legitimidad del gobierno vendrla dada entonces por el conlenido de su pollitica, por su ejercicio real del poder, que vaya en favor del interés general, que sea coincidente con la volunlad general, con relativa independencia de la forma más o menos consensuada, más o menos democrática, de que esté revestido ese poder. Podemos imaginar que si Rousseau viviera entre nosotros y se viera conirontado a optar entre cierlas democracias latinoamericanas -prácticamenle coopladas por las oligarquias locales y por el poder imperiał-y el régimen unipartidista de Cuba -que ha conseguido, no obstante su falta de pluralismo político, desarrollo, salud y educación para su pueblo - no hay mayor duda de hacia dónde se decantarla su preferencia.

\section{El debate en torno a Rousseau: una critica a sus criflcos}

Según nuestra particular forma de entender las cosas, de cada pensador más nos interesan los aciertos que los yerros, ubicar lo que aún tenga de importante por decirnos un filósofo, anles que hacer la lista de sus inexactitudes; aún con mayor razón al momento de pretender juzgar a un autor del siglo XVIII. 
Debemos hacer la crítica a algunos de sus críticos. Asl por ejemplo, al ortodoxo pro-soviético Galvano della Volpe: cuando lo refuta, habla más de Kant que de Rousseau; cuando lo reivindica, habla menos de Rousseau que de Marx. Como resultado, en su libro aparece un Rousseau -entre cita y cita del programa del PCUS- paradójicamente prekantiano y pre-manxista a la vez.

Tampoco podemos compartir la actilud de Louis Althusser, quien desde la arrogancia intelectual de un siglo $X X$ que se cree poseedor de la verdad, pareciera confrontar a Rousseau con la dogmática fómula: no es maxista, por tanto está errado. La primera parte es irrefutable: cuando Rousseau murio, Maxx no habla nacido todavia. La segunda, caso de ser verdad, es tan sólo una verdad a medias.

Aunque el análisis estructuralista de Althusser es magistral, sin proponérselo deja en evidencia conclusiones que favorecen al pensador ginebrino. El francés somete la teoría rusoniana a una crítica metodológica rigurosa, para mostrar lo que él llama "el modo de funcionamiento teórico" de El Contrato Social. No obstante, los sucesivos "desajustes teóricos" que describe, constituyen la mejor prueba de la riqueza de matices de un pensamiento que no puede menos que calificarse de pre-dialéctico. Para Rousseau la pérdida absoluta de la libertad o alienación total es ilegltima e inconcebible... pero - señala Althusseres la cláusula única del Contrato!; en conclusión: la alienación total es la solución al estado de alienación total. Segunda contradicción: el Contrato es un no intercambio, pero produce sin embargo un intercambio, $y$ además ventajoso. Tercera: el Contrato es un falso contrato, pero funciona en realidad como un contrato. Cuarta: cada interés particular contiene en si mismo al interés general, pero es a la vez su obstáculo.

Esas contradicciones de Rousseau contradicen en realidad a su crítico. Tal como ha subrayado Adolfo Sánchez Vázquez —quien tuvo el acierto de incluir en su libro un capítulo subtitulado "Hacia una concepción dialéctica de la historian - la metodologla rusoniana contiene elementos propios del pensamiento dialéctico, (que ubicarlan a Rousseau como pre-hegeliano y pre-manxista); por ejemplo, su análisis de la facultad humana de perfeccionarse, trocada en su contrario dialéctico, la facultad de corromperse. En apoyo a esta interpretación, dicho analista español radicado en México cita la autorizada opinión de Engels: "la teorla rusoniana de la igualdad no habría podido constituirse sin acudir a la negación (dialéctica) hegeliana... 20 años antes de que Hegel naciera!n.25

Althusser llega en su articulo a una conclusión correcta, aunque obvia: en Rousseau no hay una conceptualización de las clases sociales ni 
de la lucha de clases. Ello hace que -escribe Althusser- "no trate al interés general como una ideología o como un mito: lo trata como una exislencia real; por otro lado, niega lo que existe realmente: los intereses de los grupos sociales (los intereses de clase)". No obstante,deberla puntualizarse, creemos nosotros-, ello no impide que el entoque rusoniano siga teniendo su propia validez, dado que -contrariamente a lo que parece pensar Althusser- no todos los acontecimientos históricos aceptan ser reducidos esquemáticamente a un análisis de intereses de clase. Se dan también períodos de "consenso nacional" en los que se identifica un "interés general" por encima de las clases, movimientos nacionalistas en los que "un pueblo se reconoce como tal pueblo" formando su propia "voluntad general", coyunturas en las que la solidaridad internacionalista, la "fraternidad", determina la conducta de grupos significativos de personas, etc. Es decir, también a Althusser se le puede y debe hacer la pregunta que él formula a otras teorlas que no son la suya: el cuestionamiento sobre los problemas que elige y los problemas que elude.

En descargo del gran teórico francés, debemos reconocer que no debe ser lo mismo reflexionar sobre Rousseau en Parls, que hacerlo en San Salvador; hacerlo además en nuestro tiempo, cuando tan necesitados estamos de búsqueda teórica y de una renovada reflexión, aunque algunas de las "nuevas" ideas de que nos ocupamos hayan sido prematuramente expuestas hace ya cerca de 240 años.

\section{Lectura rusoniana del Acuerdo de Paz}

En primer lugar, resulta provechoso reflexionar acerca del tipo de contrato que representa el Acuerdo de Paz logrado en El Salvador. En la negociación salvadoreña, a diferencia del contrato rusoniano, ha habido dos Partes (FMLN y gobiemo) que eran preexistentes ambas y, 10 que es más importante, dos partes que juntas no alcanzan a representar a la totalidad de la nación salvadoreña. El hecho de haber dejado excluidas a otras fuerzas políticas y a la totalidad de fuerzas sociales del proceso de negociación ha sido, y sigue siendo, uno de los puntos débiles del acuerdo logrado.

Lógicamente, por haber sido el proceso de elaboración del nuevo contrato un proceso real, que dista mucho de la convención térica ideal imaginada por Rousseau, no se ha dado tampoco otra de las caracteristicas de ésta: la inexistencia, por innecesario, de un áritro. Para el contrato social salvadoreño no solamente ha sido imprescindible un árbitro, sino que además lue necesario encontrar al más cualificado, honorable y poderoso: la Organización de Naciones Unidas. 
Ello pone en evidencia la naturaleza conflictiva, no unánime, dificultosa, de la negociación y del acuerdo alcanzado. Se trata de un contrato en el que no todos los que intervienen están intimamente convencidos de no haber concedido más de lo que han obtenido finalmente. Se está muy lejos, por tanto, de las condiciones ideales del contrato rusoniano, en que es la libre voluntad y el convencimiento de realizar un intercambio mutuamente venlajoso lo que cimenta un auténtico consenso. Ello es lo que ha obligado a que la ONU haya lenido que jugar, abiertamente, la función de arbitraje, inicialmente exclulda, una vez que tanto la primitiva misión "de buenos oficios", como la posterior "mediación acliva", demostraron, en las crisis sucesivas y cada vez más graves, su impotencia frente a la compleja dinámica del proceso de paz.

Debemos matizar también que el hecho de que la ONU haya sido y siga siendo el árbitro del contrato de Chapultepec y del proceso pacificador, no significa que este Tercero intervenga desde afuera del contrato o que no deba ser considerado como una parte interesada. Es al contrario. Fue justamente a los gobiemos de los paises con más intereses en la región, a los que se invitó para que tuvieran una participación más destacada. Tanlo la conformación del inicial grupo de "Palses Amigos", como el hecho de que, a la hora de entrar en la fase de aplicación de los acuerdos, se añadiera a aquéllos el gobierno de los Estados Unidos, conformándose asl el "Grupo 4+1", es suficientemente demostrativo de ello. Es falso, por tanto, afirmar que el Acuerdo de Paz es una cuestión que atañe solamente a los salvadoreños. Ni es asl, ni puede serlo.

Si recordamos que Rousseau define que en el contrato social el compromiso de los individuos, como partes contratantes, es con toda la humanidad, veremos que hay en esle punto una coincidencia importante: también en el caso salvadoreño hay un compromiso de las partes con toda la comunidad internacional.

De ahl se desprende un derecho de intervención internacional, que es positivo desde el punto de vista de la paz, y, por tanto, de los intereses nacionales. También se deduce una obligación inversa: la comunidad internacional no puede desentenderse de la marcha del proceso pacificador salvadoreño, vinculada como está, moral y politicamente, por el tipo especial de contrato que supone el Acuerdo de Chapultepec. Esto vale para el perlodo pre-electoral, como para el perlodo postelectoral, tanto para los compromisos de tipo financiero, como para los de Indole polltica, social, de asistencia técnica, etc.

\section{El Informe de la Comlsión de la Verdad y el contrato soclal}

El compromiso de Chapultepec, este tipo de contrato que por su 
propia naturaleza atañe a toda la humanidad, tiene una faceta perticularmente sensible: el Informe de la Comisión de la Verdad. De todos los compromisos alcanzados, éste es, sin lugar a dudas, el que con mayor razón posee una dimensión que excede el ámbito de lo salvadorefío.

Lo que está en juego son principios y valores comunes a toda la humanidad, -principios defendidos desde hace casi dos siglos y medio por Rousseau-, como el del imperio de la ley, el que ésta sea universal, que no admita privilegios (impunidad), etc.; lo que está en juego es si crímenes horrendos cometidos sistemáticamente a lo largo de más de una década, contra parte de la población salvadoreña, serán efectivamente tratados por la comunidad internacional como "crimenes de lesa humanidad", si serán reconocidos por la humanidad como crlmenes en su contra.

Algunos que se oponen al Informe han señalado que la Comisión de la Verdad no puede pretender realizar en El Salvador una especie de segundo Tribunal de Nurenberg.20 Podríamos contestar, imitando el mélodo polemizador de Rousseau, que, electivamente, es asi; pero por razones y con consecuencias contrarias a las que con tal aseveración se pretenden. Dado que en El Salvador la solución negociada evitó que hubiera vencedores y vencidos, estamos, en realidad, en mejor situación para una aplicación más equitativa y sin distingos de los principios universales de la justicia. A diferencia del Tribunal de Nurenberg, la Comisión de la Verdad no sienta en el banquillo de los acusados a los vencidos; tampoco podrla hacerlo puesto que no hay tales. Por tanto, la imparcialidad y universalidad de su Informe es lanto mayor. La exigencia de cumplimiento electivo de todas las recomendaciones debe entonces, asimismo, no hacer distingos sobre a cuál bando pertenece o ha pertenecido cada implicado.

El padre jesurta Jon Sobrino ha indicado que el Informe de la Verdad debería ser considerado como un documento fundante de la nueva sociedad salvadoreña. ${ }^{27}$ Desde un punto de vista rusoniano la idea es totalmente correcta: el contrato social, la Constitución misma, deben estar asentados sobre un fundamento, el cual debe ser firme, sólido, imperecedero. Esta base no puede estar constituida sino por principios universales, derivados de la propia naturaleza humana, ésa que fundamenta el sentido de la dignidad del hombre. Ahora bien, ¿dónde, sino en los criterios y recomendaciones del Informe de la Comisión de la Verdad, están mejor concretados tales principios de justicia, principios de validez universal? Ni la misma Constitución debería, por tanto, poder prevalecer sobre él, dado que expresa y contiene principios que son anteriores y de naluraleza superior a cualquier derecho positivo, incluido el derecho cons- 
titucional.

De ahl que las recomendaciones de la Comisión de la Verdad relativas a que se efectúen otras relormas adicionales al texto constitucional, deben ser atendidas. Asimismo, las que se refieren a la depuración profunda de la Fuerza Armada, a la investigación a fondo de las redes de escuadrones de la muerte, y a la remoción y reestructuración completa del poder judicial salvadoreño, comenzando por la Corte Suprema de Justicia. Esta, debe recordarse, es duramente señalada en el Informe por su inacción, rayana en la complicidad, y por su actitud reiteradamente obstructora de las investigaciones sobre violaciones graves de los derechos humanos. La obstinación de quienes encabezan este órgano del Estado, que pretenden aferrarse a sus posiciones de poder y a la tradición de arbitrariedad que ha reinado en el sistema de juslicia salvadoreño, constituye uno de los mayores obstáculos para construir un verdadero Estado de Derecho en El Salvador.

\section{Lecciones de Rousseau para la democracla salvadoreña}

El Estado de Derecho es condición necesaria, aunque no suficiente, para la democracia. La primacia de la ley y la independencia del poder judicial respecto a los demás poderes son esenciales. Rousseau advertía que no debe confundirse la ley con la aplicación de la ley; debemos retomar esa idea, aunque en un sentido inverso a la intención rusoniana. El problema secular de El Salvador no ha sido la carencia de leyes, que las hemos tenido y algunas muy buenas, sino que ha estado centrado en su aplicación. La reflexión de Marx -a la que apunta asimismo Rousseau- de que en una sociedad desigual es injusto el derecho igual, pues en tal situación el derecho debería ser asimismo desigual, a fin de favorecer al más desprolegido, ${ }^{28}$ se vuelve casi irrelevante en el caso salvadoreño: aqui no sólo hemos tenido derecho igual, sino además aplicado desigualmente, pero en contra de los más débiles!

De la lista de causas del cruento conflicto que ha devastado nuestro país, mucho se tiende a exagerar el papel de los factores económicos, olvidando que lo que en primera instancia mueve a los pueblos son las injusticias. No es tanto la pobreza de las mayorlas - la que podría ser razonablemente aceptada en un pais que es efectivamente pobre- sino el escándalo de la ostentosa opulencia de las minorías, la que ha generado violencia. No es tanlo la situación subordinada de las clases trabajadoras, sino la forma brutal con que la clase dirigente ha ejercido su dominación, con represión cruel y con frecuencia indiscriminada, la que ha generado violencia. La injusticia generalizada, institucionalizada, sistematizada, ha sido -estamos convencidos- el primer y principal 
factor desencadenante de la guerra civil.

"Mientras un pueblo se ve obligado a obedecer y obedece, hace bien; mas si en el momento en que puede sacudir su yugo, lo sacude, hace todavia mejor", afirmaba, radical, Rousseau. Con todo, la grandeza del pueblo salvadoreño ha consistido, no únicamente en su decisión de rebelarse ante este estado de cosas y en su capacidad de resistencia frente a la opresión, sino principalmente en su fuerza moral para dar la lucha desde ideales social y éticamente válidos. Fácilmente hubiera podido deslizarse hacia posturas cĺnicas, egoislas, laltas de valores morales. Existe también una forma amoral de rebelarse, ésa que reflejaba el inolvidable Maquiavelo, quien mucho antes que Rousseau fue también a su modo un inconlormista con el orden existente: "le dan el falso nombre de ganancias a lo que han robado con engaños y violencia", "los siervos fieles son siempre siervos, y los hombres buenos son siempre pobres" ${ }^{2 \theta}$ Rousseau sentía una rara admiración por este autor llorentino del siglo $X V I$, de quien hacla una poco usual interpretación: "Maquiavela, fingiendo dar lecciones a los reyes, se las ha dado muy grandes a los pueblos". Sin embargo, la obra rusoniana se encaminó, contrariamente a Maquiavelo, a la conceptualización de firmes ideales éticos del hombre y de la sociedad, sobre los que sentar las bases para una sociedad alternativa.

Justamente el tipo de lazo indisoluble entre ética y política que está a la base de la propuesta rusoniana, debe ser retomado en El Salvador, donde la postguerra está mostrando vacilaciones y retrocesos en este campo. Han empezado a aparecer claras muestras de predominio de "intereses particulares" de parte de dirigenles y partidos politicos, incluidas las fuerzas opositoras. El llamado rusoniano contra la presencia de "asociaciones particulares" en el seno del Estado, sigue siendo actual, asi como su advertencia contra la delensa a ultranza de intereses particulares - bien sean éstos privados, bien sean éstos de tipo gremial o partidarista- como destructores de la "voluntad general", como manipuladores de la soberanía popular, propensos a prometer lo que después no pueden o no quieren cumplir. "Nunca se corrompe al pueblo -reflexionaba amargamenle Rousseau- pero frecuentemente se le engaña".

Si la tendencia a despreciar las consideraciones éticas en la práctica politica llegase a consolidarse, el futuro democrático en EI Salvador va a sufrir una grave depreciación. Si la democracia no amplia horizontes, si se conforma con un paisaje que se observa hoy por hoy estrictamente limitado, si no trasciende lo que es por el momento aparentemente posible, la caida en un pragmatismo y conformismo generalizado será la 
muerte del potencial de vitalidad democrática. En este caso, el espiritu rusoniano será más actual y necesario que nunca, su intuitiva rebeldla, que lo llevó -como afirma Agnes Heller, la erudita analista húngara"a rechazar el presente y la simiente del futuro", a rechazar un presente feudal y un futuro burgués. ${ }^{30}$ Parecidamente, no era tolerable en EI Salvador una situación de dictadura oligárquica y tampoco será aceptable un futuro que se limitase a las fórmulas convencionales de la democracia burguesa.

\section{NOTAS}

1. Entre estos pocos, debe mencionarse a Manuel Montobbio, -quien fuera por tres años Primer Secretario de la Embajada de España en San Salvador- el cual, en una interesante interpretación, identifica acuerdos de paz coń contrato social. Esle vendría a superar un previo "eslado de la naturaleza", expresado en la siluación bélica precedente: tras "la brutalmente negada victoria electoral de Duarte (1972)... se inicia, a partir de ahl... el retorno al eslado de la naturaleza". Para Monlobbio, en El Salvador ha sido preciso - pasar por la catarsis de la guerra civil para contar con un contrato social, a todos los ciudadanos preferible al estado de la naturaleza". Con ese marco, el autor se lormula preguntas como: "Les posible el relomo al conlrato social por la vía del contrato mismo, de la negociación que lleva lodo contralo? ¿es posible un acuerdo de paz en El Salvador? (...) ¿será la salvadoreña una sociedad viable? (...) ¿basla el contrato social o es necesario un minimo contenido sustancial?" (Montobblo, 1992).

2. A lo mismo apunta la notable reflexión teórica de Edelberto Torres Rivas, quien nos propone "interrogarnos acerca de las condiciones en que la democracia política puede ser una posibilidad histórica", dado que "fueron necesarias condiciones particulares, algunas de ellas irrepetibles, para alcanzar los niveles de participación popular, pluralismo ideológico, tolerancia al adversario, etc., que exhiben las grandes democracias hoy día." Ello significarla que "la legitimidad del orden polftico capitalisla" haya logrado un control ideológico y cultural "que oculta la relación de desigualdad existente y por lo tanto, encubre la confliclividad inherente a las relaciones de clase, opuestas y contradictorias por su propia naturaleza." ( Torres Rivas, 1992; págs. 12 a 15).

3. Sánchez Vázquez, 1970; pág. 15

4. Ibid; págs. 28,18 y 19

5. Las citas textuales de Rousseau las colocamos entre comillas $y$, excepto cuando se indique otra fuente, pertenecen lodas a la obra "El Contrato Social", cuya relerencia bibliográlica puede consultarse al final del articulo.

6. Sánchez Vásquez, 1970; pág. 29

7. Ibid, pág. 31 
8. Igualmente ocurre con la lógica racionalista, típica de la llustración, que es utilizada por el ginebrino a fin de volverla contra si misma y mostrar la esencia irracional, tanlo del mundo leudal, como de la sociedad burguesa llamada a reemplazarlo.

9. Véase al respecto lo expresado por Rousseau a lo largo del Libro Segundo de "El Contrato Social".

10. A esa paradoja Althusser la denomina el Desajuste I de la teorla de Rousseau, que hace del contrato social rusoniano, un no intercambio. Para Althusser, "la genialidad de Rousseau está también en que supera, al volverlo superfluo, el problema de la necesidad de un árbitro", (ingenuamente negada por Hobbes), pues entre los individuos y el soberano no se requiere de ábitro alguno, dado que el soberano son los mismos individuos; teóricamente resulla consistente: "no se requiere de un Tercero, puesto que en realidad no hay un Segundo." (Althusser, 1972; págs. 79 y 82 ).

11. Otra influencia direcla de Rousseau sobre la revolución francesa, por lo demás de sobra conocida, fue la Declaración de los Derechos del Hombre y del Ciudadano. De ella arrancará la actual conceplualización de derechos humanos, entendidos como derechos naturales con preeminencia sobre el derecho positivo. Lo cual no invalida que, para Rousseau, éstos no son anteriores a la sociedad, pues "sólo en sociedad surgirán los derechos de los hombres como hombres". (Béneke; pág. 119).

12. Sánchez Vázquez, 1970; págs. 48 y 49

13. Allhusser, 1972; pág. 97

14. Colangelo, 1972; pág. 225

15. González, 1987; págs. 247 y 283

16. Dominguez, 1978

17. González, 1987

18. Fonseca, 1990

19. Domínguez, 1978

20. della Volpe, 1963; págs. 68, 41, 34 y 35

21. Colangelo, 1972; págs. 202 y 191

22. Maxx, 1875; pág. 35

23. Colangelo, 1972; pág. 217

24. En la época medieval, la ideología cristiana reaccionaria enlatizaba que la lierra constituye un "valle de lágrimas" y que los pobres deben aceptar con resignación y esperanza su siluación miserable, pues será en el más allá, en el cielo, donde serán bienaventurados y gozarán del favor divino. Ha costado siglos de lucha ideológica el que se abriera paso en el seno del cristianismo una corriente progresisla, que plantea el advenimiento de senales que anuncian el Reino de Dios como un asunlo terrenal, del más acá, y que valoriza el compromiso y la resistencia a la opresión frente a las tradicionales "virtudes crislianas" de la resignación y el conformismo.

Las luchas obreras de la segunda mitad del siglo XIX, que haclan tambalear no sólo las estructuras de poder, sino también la ideologia pseudoreligiosa que ayudaba a sostenerlas, inspiraron la imagen del "asalto al cielo", utopla que pareció a punto de realizarse en 1917, cuando el triunfo de la revolución rusa hacia pensar que podrla surgir un Estado obrero, una 
democracia solialista, una especie de "paralso de los trabajadores".

25. Sánchez Vázquez, 1970; págs. 37 y sigulentes

26. En Nurenberg, al lérmino de la segunda Guerra Mundlal, como es sabldo, fueron enjulclados y condenados los criminales de guerra nazls; es decir, los vencidos. AhI no se hablo de "los excesos" cometldos por los combatientes de los paises aliados, nl de los mortiferos bombardeos contra objettvos civiles en las cludades alemanas, ni de la criminal decisión de lanzar la bomba atómica sobre dos ciudades japonesas...

27. Sobrino, 1993

28. Marx, 1875

29. Heller, 1980

30. Heller, 1980; pág. 26.

\section{BIBLIOGRAFIA}

Althusser, Louis:"Sobre el Contrato Social", Levi-Strauss y otros: "Presencia de Rousseau", Ed. Nueva Visión, Buenos Aires, 1972.

Beneke, Cristina M.: "Fundamentación teórica de los derechos humanos desde la realidad salvadoreña", Tesis Licencialura Filosolía, 1985, UCA.

Colangelo, Rocco:"Igualdad y sociedad de Rousseau a Man", Levi-Strauss y otros: "Presencia de Rousseaul Ed. Nueva Visión, Buenos Aires, 1972.

della Volpe, Galvano:" Rousseau y MaxX', Ed Platine, Buenos Aires, 1963.

Dominguez, Manuel:"Rousseau y la reconstrucción de la sociedad, ECA, Jullo 1978, UCA Ed.

Engels, Friedrich:"Anti-DÜhring", Ed. Grijalbo, Barcelona, 1977.

Fonseca, Carlos A.:"Resgos esenclales de una sociedad legitima según el pensamiento de Rousseau", Tesis Licenclatura Filosolla, 1990, UCA.

González, Antonio:"Prologo" a "El Contrato Social", UCA Ed., San Salvador, 1987

"Introducción a la Filosofia", UCA Ed., San Salvador, 1987

Heller, Agnes:"El hombre del renacimiento", Ed. Península, Barcelona, 1980.

Maxx, Karl: "Crítica al Programa de Gotha", Ed.Anteo, Buenos Alres, 1973

Montobbio, Manuel:Construcción nacional y crisis en El Salvador: una aproximación contractual a la problemática salvadoreña", en "Tiempo de Paz", N²4-25, verano-otoño 1992; Ed. Movimiento por la Paz, el Desame y la Libertad; Madrid, 1992.

Rousseau, Jean Jacques:"Discurso sobre las Ciencias y las Artes", Ed. Aguilar, Buenos Aires, 1962.

"Discurso sobre el origen y fundamentos de la desigualdad entre los hombres", Ed. Aguilar, Madrid, 1973.

"El Contrato sociar, UCA Ed., San Salvador, 1987.

"Emilio o de la educación", Ed. Porrúa, México, 1978.

"Las Confesiones", Editora Nacional, México, 1967.

Sánchez Vázquez, Adolfo:"Rousseau en México", Col. 70, Ed. Grijalbo, México, 1970. 
Sobrino, Jon:"Reflexiones teologicas sobre el informe de la Comisión de la Verdad', ECA abril-mayo 1993, UCA Ed.

Torres-Rivas, Edelberto: “El tamaño de nuestra democracia”, Isımo Editores, San Salvador, 1992. 